\title{
Influence of Laser Pulse Number on the Ablation of Cemented Tungsten Carbides (WC-CoNi) with Different Grain Size ${ }^{\dagger}$
}

\author{
Shiqi Fang 1,2,3 (1D), Chia-Jui Hsu ${ }^{4}(\mathbb{D})$, Sven Klein ${ }^{3}$, Luis Llanes ${ }^{1,2, *}$, Dirk Bähre ${ }^{3}$ \\ and Frank Mücklich 4 \\ 1 CIEFMA-Departament de Ciència del Materials i Enginyeria Metal.lúrgica, Universitat Politècnica de \\ Catalunya, EEBE—Campus Diagonal Besòs, 08019 Barcelona, Spain; shiqi.fang@uni-saarland.de \\ 2 Barcelona Research Center in Multiscale Science and Engineering, Universitat Politècnica de Catalunya, \\ 08019 Barcelona, Spain \\ 3 Institute of Production Engineering, Saarland University, 66123 Saarbrücken, Germany; \\ sven.klein@uni-saarland.de (S.K.); d.baehre@mx.uni-saarland.de (D.B.) \\ 4 Institute of Functional Materials, Saarland University, 66123 Saarbrücken, Germany; \\ chiajui.hsu@uni-saarland.de (C.-J.H.); muecke@matsci.uni-sb.de (F.M.) \\ * Correspondence: luis.miguel.llanes@upc.edu; Tel.: +34-93-4011-083 \\ $+\quad$ This paper is an extended version of our paper published in Sixth World Tribology Congress (WTC 2017).
}

Received: 6 December 2017; Accepted: 16 January 2018; Published: 20 January 2018

\begin{abstract}
The ultra-short pulse laser has attracted attention as an advanced tool for functionalizing surface topography, since it has high accuracy and results in little damage. In a previous study, some innovative patterns were introduced on cemented carbide surfaces, such as dimples, which are commonly used as oil reservoirs for bearings. The accuracy is not only related to the inherent features of the laser, but also to the machining processes. Within this context, this study aims to investigate the influence of machining parameters (i.e., pulse number in this study) on the ablation mechanism and resulting surface integrity. Two cemented carbide grades, possessing similar chemical composition but different grain size (small and large), are machined using a femtosond laser set-up with variant pulse number (1-20). The geometrical properties of the produced structure and surface integrity are statistically investigated using different microscopy techniques. It is found that the dimple depth is approximately proportional to the pulse number for both grades, and the coarse grade leads to a higher rate of depth increase. Damage is found in the form of melting and cracking for the binder and the grains, respectively; but this is more pronounced for large-grain grade in terms of the scale and depth. However, these observations are only found at a very superficial position.
\end{abstract}

Keywords: cemented carbides; ultra-short pulse laser; laser surface texturing (LST); surface integrity; damage

\section{Introduction}

Cemented carbides are composites consisting of a hard phase (usually WC) bound by a soft and tough metallic one (commonly Co- and/or Ni-based). Cemented carbides are often used as cutting tool materials thanks to their adequate hardness in combination with toughness and high thermal resistance. Cemented carbide is harder than most steels, and its hardness can reach 1600HV30 [1,2]. Therefore, it is widely used as a cutting tool material in industry, and its application is also extended to other domains, such as tribology, aeronautics and medicine [3-5]. A typical application of cemented carbides is the milling of steel; however, they are also used in fine machining. They are, for example, applied in the honing process. When honing small diameters, the honing tools are connected to an adjustable honing stone and two guiding stones, which are firmly attached to the workpiece. These 
are ground towards the dimension to be honed, and need to fulfill high demands with regard to dimension and form exactness over the whole service life [6]. The application of a guide stone made of cemented carbides can satisfy the requirements mentioned above as a supporting part, but damage can sometimes occur on these cemented carbide supporting parts, due to excessive friction or surface defects between the contact surfaces.

Surface treatment of structural materials has received increasing attention, since it usually yields improved tribological performance, significant life extension, and an even wider field of application [7-9]. In a previous study of the authors, laser surface texturing (LST) was implemented to modify and produce specific patterns on the contact surfaces of supporting parts made of cemented carbide. Compared to non-textured surface, lower friction was achieved by these laser-produced line-like structures in the tribological test $[10,11]$. These innovative surface structures were also applied in a simulation of inner honing processes by the authors, and it was found that guide stones with such innovative surface structures are favorable for obtaining a more stable honing system by lowering the friction [12]. Regarding surface modification by LST, surface quality resulting from laser beams can be influenced by the inherent properties of the laser beams. Previous studies regarding surface quality have mostly focused on the influence of the inherent properties of laser beams, such as pulse duration, pulse energy and wavelength [13-15]. However, laser processing conditions, especially the interactions and correlation between the machining parameters and the microstructural properties of the material, can also play an important role in laser ablation and, consequently, on the induced machining quality [16-19]. Hence, it is necessary to study and optimize the laser processing parameters in order to reduce the induced defects and to increase the integrity of the modified cemented carbide surfaces, especially for cases of repetitive, gradual ablation by laser beams at the same location. In this study, the dimple is chosen as the studied structure. Dimples are one of the most classic surface texture features used in the tribological system. They are widely used on contacting surfaces to improve their frictional performances. Bearings are clear examples of this, where the dimples act as micro-reservoirs that offer supplementary lubricants and local lifting pressure in the tribological system [10,20,21].

The aim of this research work is to investigate the influence of laser machining parameters on the ablation of cemented carbide; especially the pulse number, which directly determines the material ablation rate. In doing so, a femtosecond laser set-up is implemented to produce dimple-like structures on the surfaces of two different cemented carbide grades, which have approximately identical chemical compositions, but different grain sizes. Subsequently, geometrical properties of the produced dimples are statistically characterized. Surface integrity assessment is complemented by further inspection of the laser's influence on the microstructure in order to understand its ablation and damage mechanisms. In this study, laser scanning microscopy (LSM) is conducted to measure the structural dimensions. Focused ion beam (FIB) in combination with scanning electron microscopy (SEM) is used to investigate the microstructural changes of the modified surfaces.

\section{Materials and Experimental Aspects}

Two cemented carbide grades are selected as studied materials (Table 1). Both cemented carbide grades used in this study possess $14 \mathrm{wt} \%$ cobalt and, in addition to this, $14 \mathrm{wt} \%$ nickel. VN76 has a small grain size (less than $2.5 \mu \mathrm{m}$ ), and VN77 has a large one (larger than $5 \mu \mathrm{m})$. All the samples are subjected to fine polishing prior to laser treatment. Figure 1 shows the polished surfaces of the cemented carbide grades, where the dark phase represents the binder and the bright phase represents the WC grains.

Table 1. Microstructural characteristics and properties of the cemented carbides.

\begin{tabular}{cccccc}
\hline Material & Grain Size $(\boldsymbol{\mu m})$ & Co $(\mathbf{w t} \%)$ & $\mathbf{N i}(\mathbf{w t} \%)$ & Density $\left(\mathbf{g} / \mathbf{c m}^{3}\right)$ & Hardness $(\mathbf{H V} 30)$ \\
\hline VN76 & $<2.5$ & 14 & 14 & 12.77 & 710 \\
VN77 & $>5$ & 14 & 14 & 12.82 & 610 \\
\hline
\end{tabular}




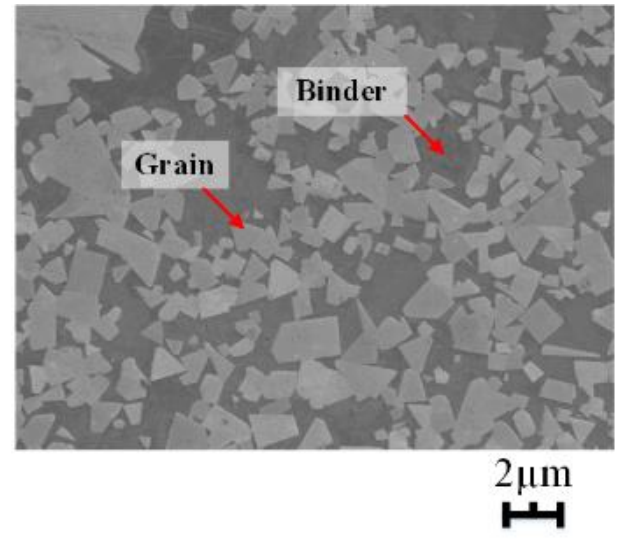

(a)

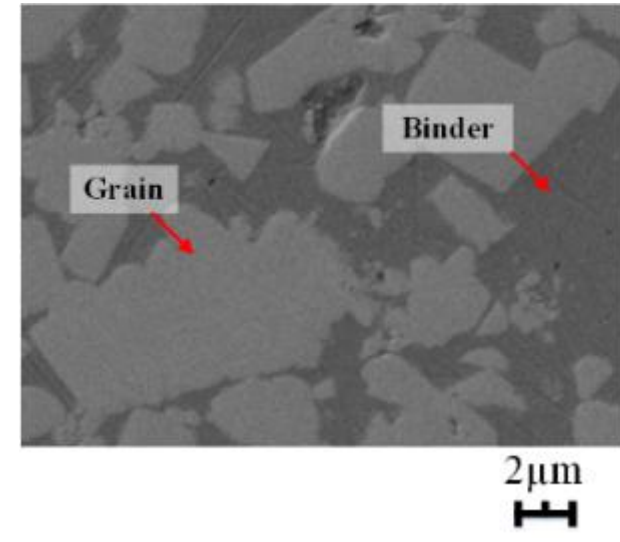

(b)

Figure 1. Polished surfaces of cemented carbide grades, images taken by SEM: (a) VN76 (small grains); (b) VN77 (large grains).

A femtosecond laser (Ti:Sapphire), in combination with an auto stage, is employed to produce dimples on the cemented carbide surfaces. The laser beam produced by the femtosecond laser set-up passes through the lens and is then focused and applied on the target sample, which is fixed on the auto stage. Dimples are produced on the sample surfaces using the aforementioned machining parameters. The wave length of the laser beam is $800 \mathrm{~nm}$, pulse repetition frequency (PRF) is $1000 \mathrm{~Hz}$, pulse duration is $150 \mathrm{fs}$ and average power is $2.6 \mathrm{~W}$ (Table 2).

Table 2. Laser parameters used for dimple production.

\begin{tabular}{cccccc}
\hline Laser Type & Laser Source & Pulse Duration (fs) & Wave Length $(\mathbf{n m})$ & PRF (Hz) & Average Power (W) \\
\hline fs-laser & Ti:Sapphire & 150 & 800 & 1000 & 2.6 \\
\hline
\end{tabular}

Pulses, varying from 1 to 20, are processed on the sample surface during laser treatment, and the produced dimples are arranged in an array on the cemented carbide surfaces (Figure 2a). For each pulse number, ten repetitions are carried out. Two geometrical parameters of the dimples are measured and statistically analyzed: diameter and depth. Dimple diameter $(d)$ is measured along the horizontal direction. Depth $(h)$ is measured in the middle of the dimple from its bottom to its top level (Figure 2b).

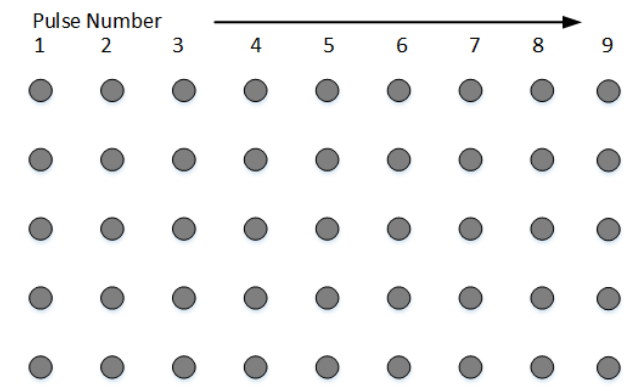

(a)

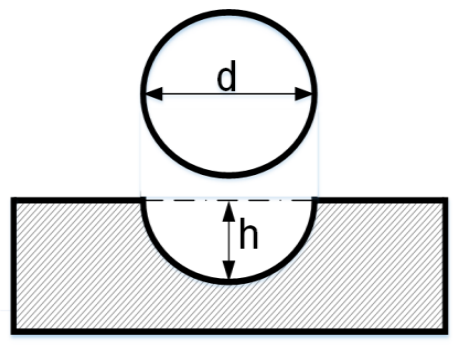

(b)

Figure 2. Characterization of geometrical properties of laser produced dimples: (a) arrangement of the dimples; (b) diameter and depth.

\section{Results and Discussion}

Figure 3a demonstrates the produced dimples with identical machining parameters on each column (Table 2), including repetitions. Laser pulses increase from 0 to 20 along the row, and the 
laser-affected zone is correspondingly increases slightly from left to right. Figure $3 \mathrm{~b}$ shows one dimple produced by 10 pulses, characterized by LSM; the laser-reaction zone is situated in the center of the dimple, and the dimple is surrounded by a grey circle, which signifies the laser-affected zone.

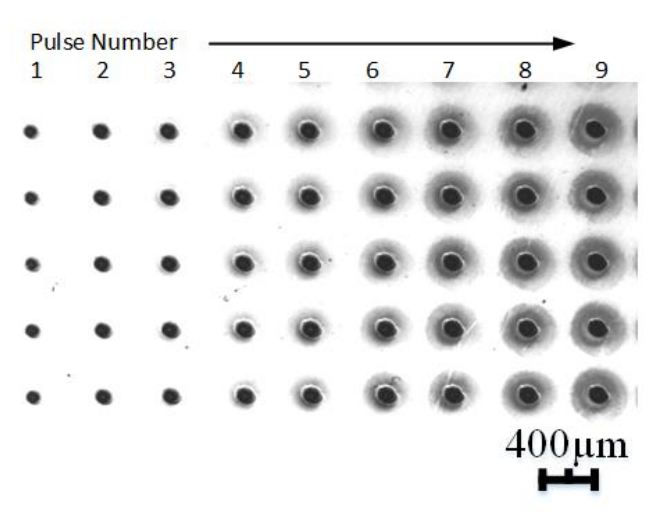

(a)

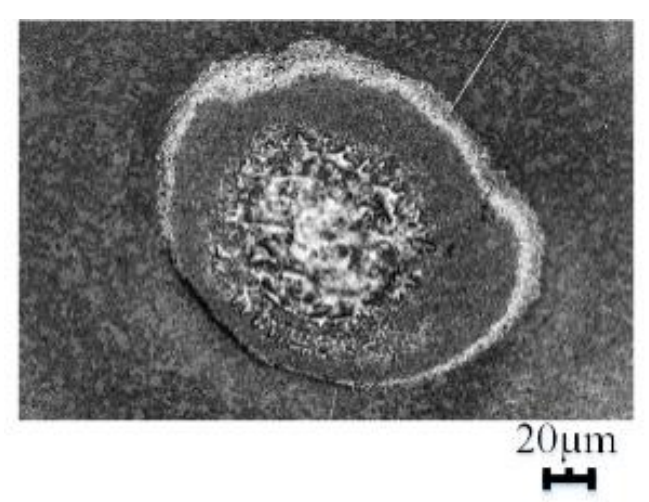

(b)

Figure 3. (a) Arrangement of the laser-produced dimples on the cemented carbide surface; and (b) one dimple characterized by LSM.

\subsection{Measurement of Geometrical Properties}

Figure 4 illustrates the evolution of dimple geometrical properties as a function of the increasing pulse numbers. For both cemented carbide grades VN76 (small grains) and VN77 (large grains), the measured diameters exhibit similar features: they have a slight increase along with the pulse number at the beginning. The diameters fluctuate between $30 \mu \mathrm{m}$ and $40 \mu \mathrm{m}$ for VN76 (small grains) and $20 \mu \mathrm{m}$ to $30 \mu \mathrm{m}$ for VN77 (large grains), and a slight increase of the diameters can be observed when the pulse number increases from 1 to 10 for the former and from 1 to 13 for the latter (Figure 4a). The initial diameters of the dimples produced on both cemented carbide grades using identical laser beams are slightly distinct from one another. This might be an issue related to the microstructural differences of the cemented carbides. The diameter increase could result from the change of the laser-matter reaction position; during the first pulse, the reaction position is overlapped with the laser beam focus point, but the reaction position moves forward along with the material ablation. Due to the Gaussian profile of the laser beams, the laser-affected zone also slightly expands. However, the expansion becomes less pronounced when the applied pulse number is more than 10 , because the energy decreases at the bottom of the Gaussian profile, or distant from the focus point.

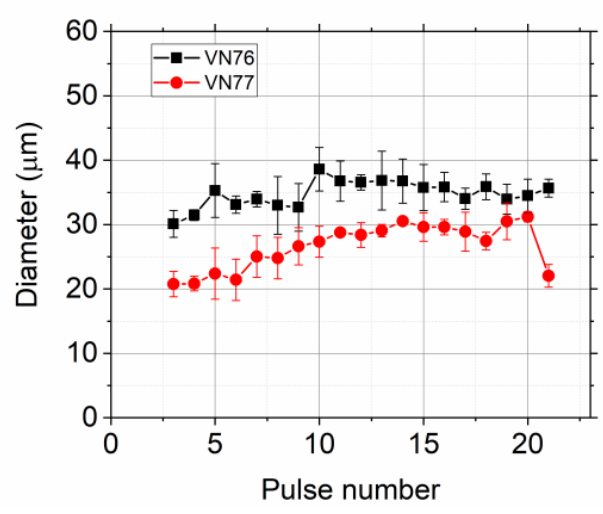

(a)

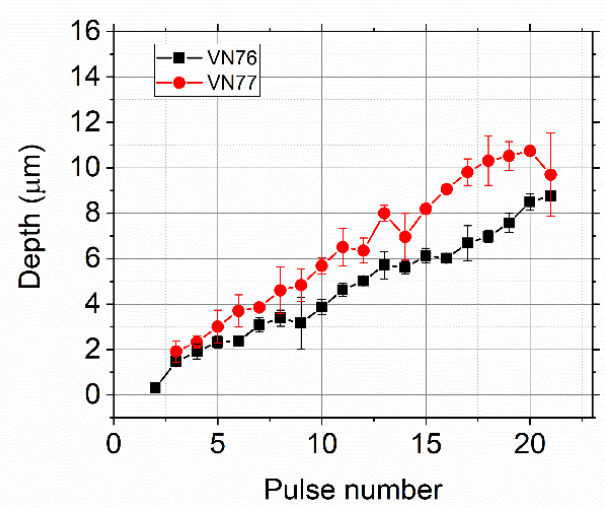

(b)

Figure 4. Dimple geometrical properties as a function of pulse number: (a) diameter; (b) depth. 
Figure $4 \mathrm{~b}$ illustrates the depth increase of the dimples as a function of the pulse number. It is found the depth increases for both cemented carbide grades are approximately proportional to the pulse number. The absolute depth increase for VN76 (small grains) is about $8 \mu \mathrm{m}$, i.e., $0.4 \mu \mathrm{m}$ for each applied laser pulse, and that for VN77 (large grains) is about $11 \mu \mathrm{m}$, i.e., $0.55 \mu \mathrm{m}$ for each pulse. The increase of VN77 (large grains) is more obvious than that of VN76 (small grains). A similar observation was made by Haustrup et al. [19], that the ablation threshold increases when grain size decreases. Therefore, the depth increase of the dimple on VN76 (small grains) is less pronounced than that on VN77 (large grains) due to the higher ablation threshold of VN76 (small grains).

It has been suggested by Leitz et al. [22] that laser ablation occurs, and evaporation dominates in the laser-reaction zone, whereas the material only melts to liquid in the laser-affected zone. The particles and droplet surrounding the dimple could be related to the overheated liquid, which results in a metastable liquid-vapor state leading to phase explosion. In this state, a large number of vapor nuclei are developed, and cause the projection of droplets during rapid evaporation [23]. As a consequence, both the liquid state at the outer circle and the phase explosion caused the formation of the crown-like structure. Figure $5 a$ exhibits a schematic illustration of the crown-like structure. Figure $5 b$ shows the evolution of the crown-like structures when the applied pulse number increases. The induced structures were not found when only a few pulses were applied in the femtosecond regime. When the pulses pass a certain level, the height of the crown-like structure can be measured, but still only at a very weak level (less than $2 \mu \mathrm{m}$ ). This observation can be explained by the fact that the increase of the dimple depth causes the laser-matter reaction position to move away from the laser beam focus when the pulse number increases, and the energy applied at the dimple boundary decreases and causes insufficient material ablation. Meanwhile, more melted material is pushed away from the center to the side when the pulse number increases. As a consequence, the redeposition, i.e., the crown-like structure, is more important at a high pulse number. The increase in crown height of both cemented carbides exhibits a similar rate, which suggests that the formation of the crown-like structures is independent of the microstructure of the cemented carbide. Nevertheless, the crown-like structures are usually considered to have important side effects with regard to the machining accuracy, and also to the surface integrity. Therefore, it is preferable to use fewer pulses to avoid the appearance of the crown-like structures.

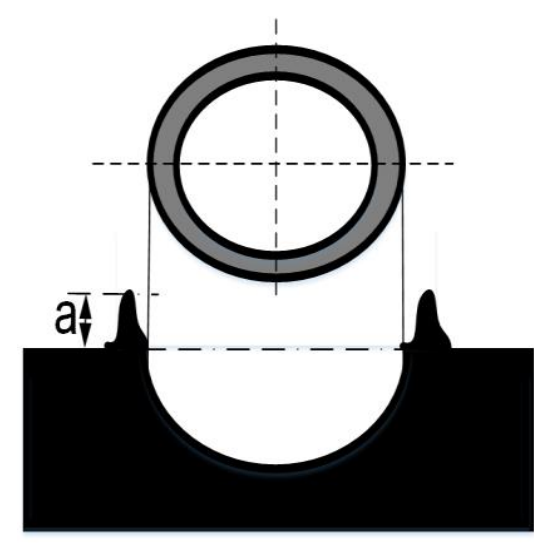

(a)

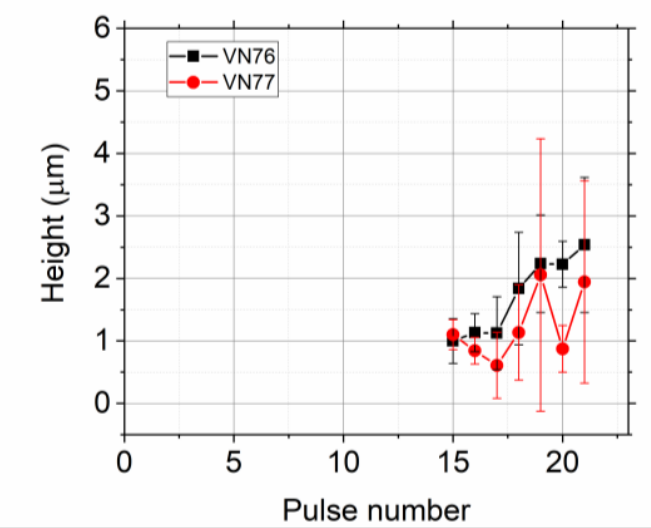

(b)

Figure 5. (a) Schematic illustration of the induced crown-like structure; and (b) height of crown-like structure as a function of pulse number.

\subsection{Assessment of Surface Integrity}

The dimples produced on these two grades by ten laser pulses were characterized by FIB-SEM, aiming to understand the mechanism of laser ablation by inspecting the modification of surface morphology and microstructural change at the subsurface. 


\subsubsection{Dimples Produced on VN76 (Small Grains)}

It is observed that surface melting occurred, and molten droplets were projected away from the dimple area towards the surroundings (Figure 6a). In addition to the projection of droplets, other side effects, such as pinpoints, can also be observed (Figure 6b). Cross-sectional analysis was conducted from the edge to the center of the dimple to inspect the microstructural change of the subsurface (Figure 6c,d). Some cracks and pores emerged at the subsurface, and the cracks go through not only the WC grain, but also the junction of two WC grains. The subsurface was only slightly affected by the laser beams, and was covered by a thin layer of solidification. The layer was less than $1 \mu \mathrm{m}$, and some pores appeared in this thin layer during the solidification process.

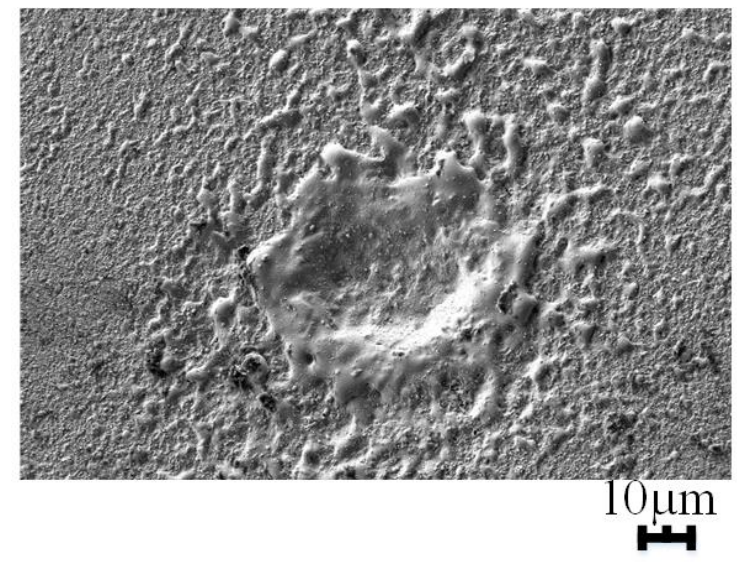

(a)

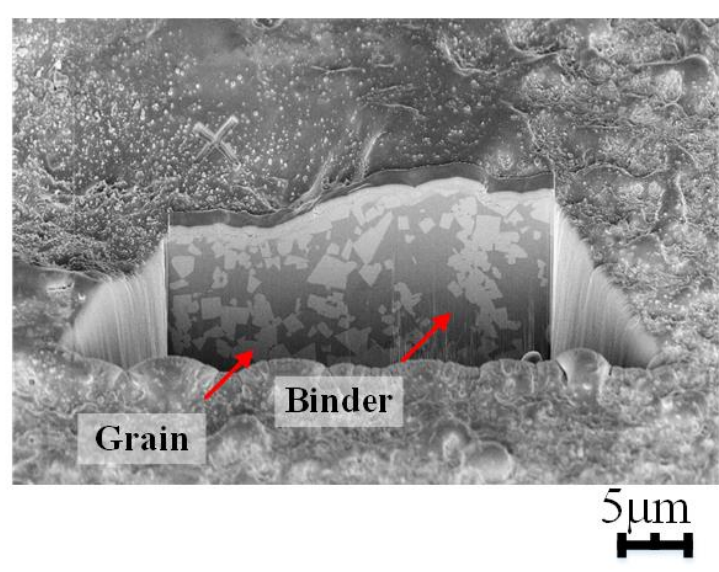

(c)

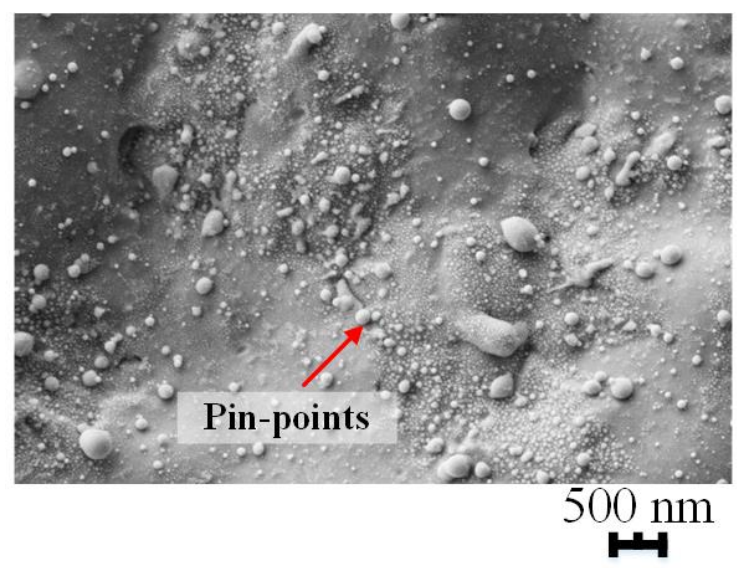

(b)

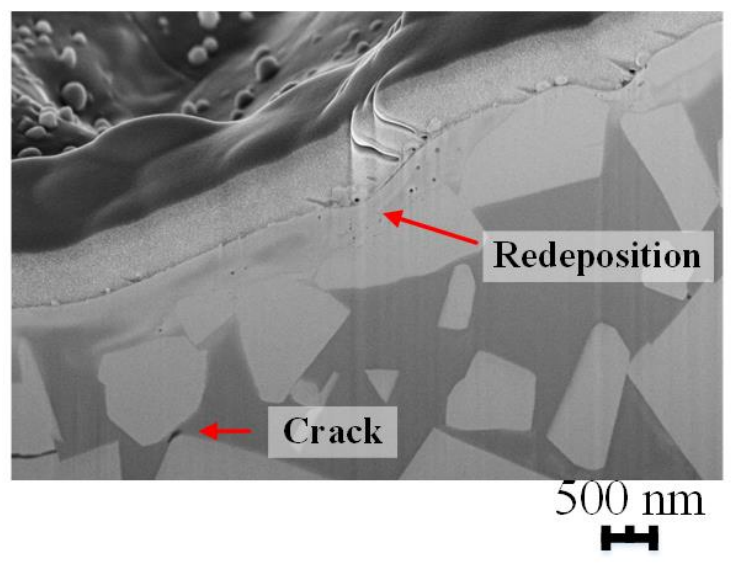

(d)

Figure 6. (a,b) Surface morphological characterization; (c,d) cross-sectional characterization of the dimples produced by 10 pulses on VN76 (small grains).

\subsubsection{Dimples Produced on VN77 (Large Grains)}

Figure 7a illustrates the surface morphology of the dimples produced by 10 laser pulses on VN77 (large grains). Similar observations were made as in the case of VN76 (small grains). The dimples were shaped by the laser beam with a Gaussian profile, whereby the material is melted and pushed aside from the dimple center, where the energy maximum of the laser beam is. However, the laser-affected zone for VN77 (large grains) seems to be smaller than that of VN76 (small grains), taking into account the area of melting and redeposition. Meanwhile, the damage on the surface of VN77 (large grains) induced by laser beam with identical configuration was more pronounced (Figure $7 \mathrm{~b}$ ). At the affected surface, not only droplets and pinpoints were found, but cracks also appeared. Cross-sectional analysis 
was conducted from the dimple edge to the center (Figure 7c). When zoomed in, as shown in Figure 7d, it can be seen that grains at the subsurface were mainly damaged by cracks. Most cracks were found penetrating into the grains, although some had also occurred at the borders between grains. It is also found that grains were slightly melted at the very top position, where the energy of laser beam was at its maximum. However, the binder was largely melted and redeposited between the broken grains. These observations suggest that the two components of cemented carbide, i.e., grains and binder, have quite different damage mechanism; grains are mainly damaged by cracks, and much more aggressively than the binder, which is mainly damaged by melting. On the other hand, broken grains might cause great damage, due to their brutal rupture and the following consequences, such as stress concentration and fissure propagation, etc. All these phenomena were observed at the subsurface, at a depth of more than $4 \mu \mathrm{m}$ for VN77 (large grains), but of only $1 \mu \mathrm{m}$ for VN76 (small grains), following the application of laser beams at identical positions with ten repetitions. This observation implies that the repetitive pulses applied at the same place slightly accumulate the side effects for the small grain grade, and the laser beams induce less damage in the small grain grade in terms of the influencing scale and depth. The microstructure, especially the grain size of the cemented carbides, plays an important role in the occurrence of surface damage induced by the laser beams. Therefore, it is advisable to use a low level of laser energy to ablate the large grain grade, whereby the binder is removed by melting and the grains are consequently peeled off.

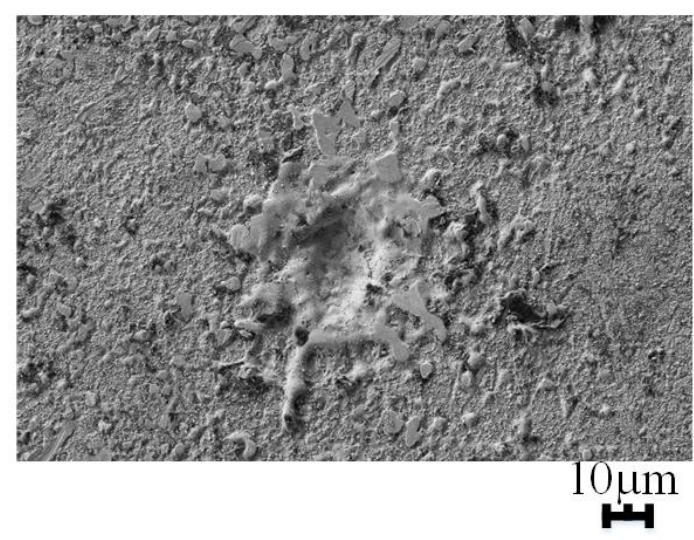

(a)

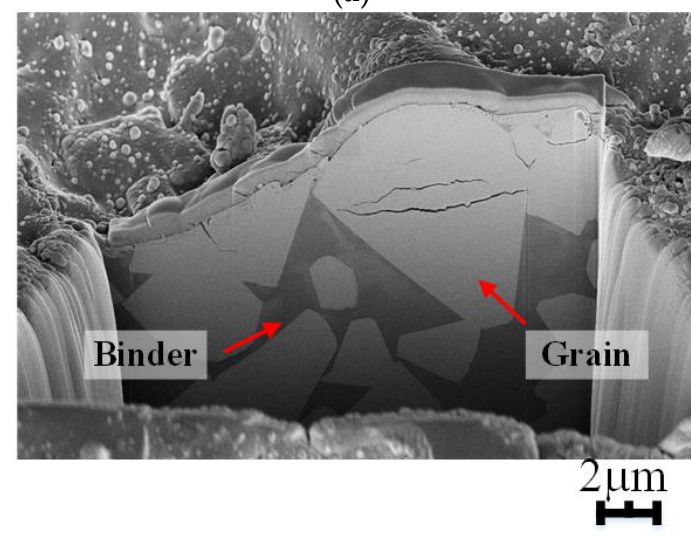

(c)

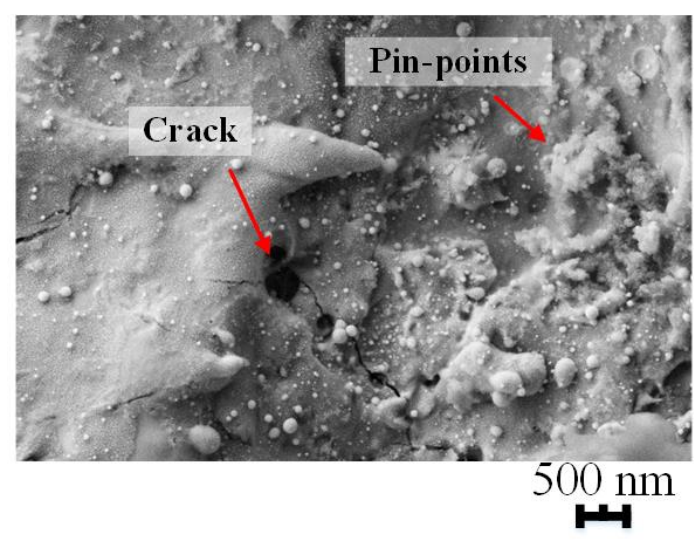

(b)

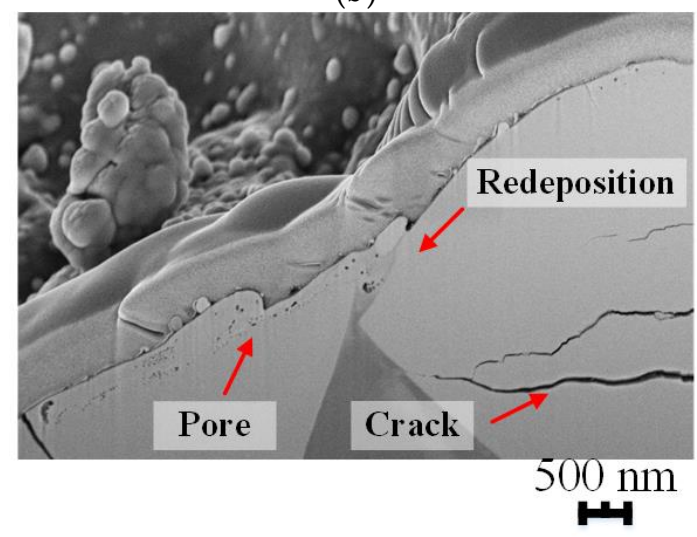

(d)

Figure 7. (a,b) Surface morphological characterization; (c,d) cross-sectional characterization of the dimples produced by 10 pulse on VN77 (large grains).

\subsubsection{Chemical Composition of the Affected Zone}

The chemical composition of the laser-produced structures on the surface of VN77 (large grains) was characterized by the Energy-dispersive X-ray spectroscopy. For the dimple produced by 1 pulse, 
two analysis positions were selected on its surface (Figure 8a): one was located in the laser-matter reaction zone, and one was located in the laser-affected zone. It was found that the reaction zone was covered by a layer of the melted binder, i.e., a mixture of cobalt, nickel and a little chrome. Oxygen was not detected at this position, which proves that oxide was not produced by interaction with the femtosecond laser. At the laser affected zone, WC grains were slightly contaminated by the melted binder, since a small quantity of nickel was detected (Figure 8b). For the dimple produced by 15 pulses, two analysis positions were selected along the cross-section: one was located near the surface of the dimple bottom and the other one at the subsurface of the dimple (Figure 8c). It was found that the bottom surface (Position B) was covered by a layer containing elements of the binder (Cobalt, Nickel and Chrome) and grains (Tungsten and carbon). Oxygen was not detected either, which confirms that the femtosecond laser did not provoke any oxidation reactions. The deeper area (Position A) seemed to be intact from the laser beam, since only binder elements were evidently detected, except that a little tungsten still appeared, which might have resulted from the presence of WC grains within the X-ray generation region (Figure $8 \mathrm{~d}$ ).

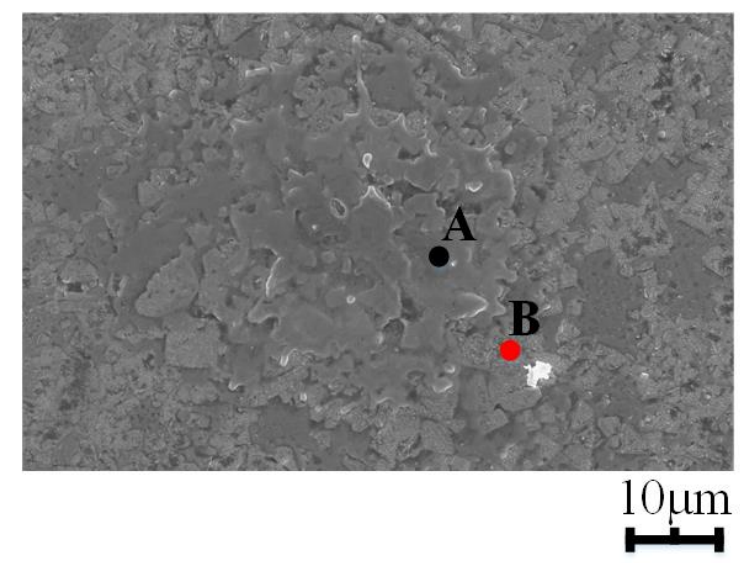

(a)

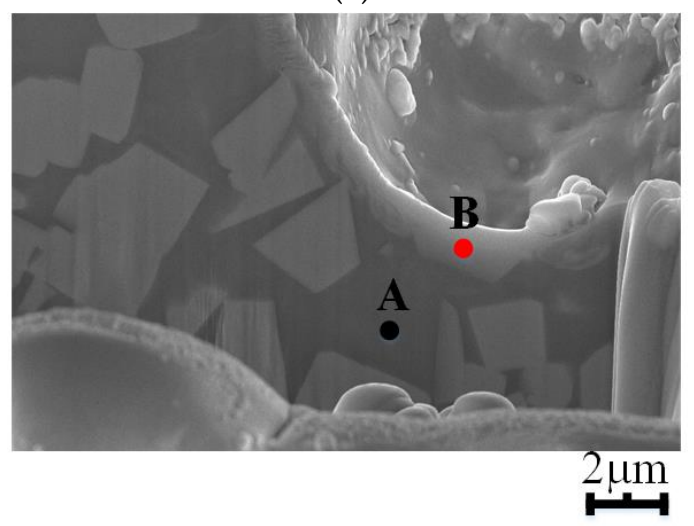

(c)

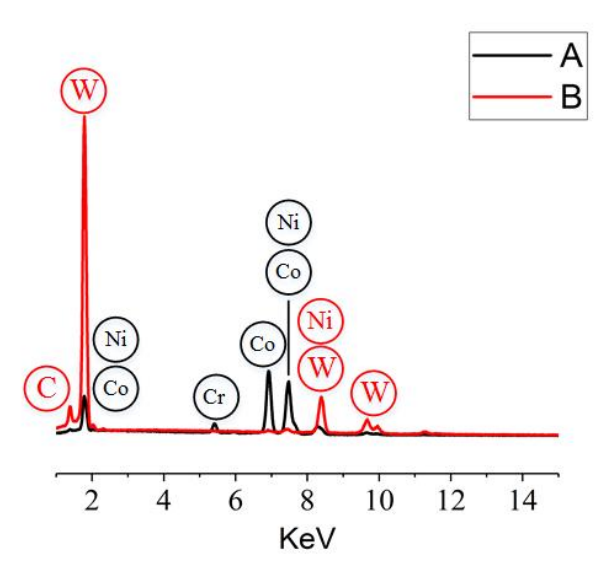

(b)

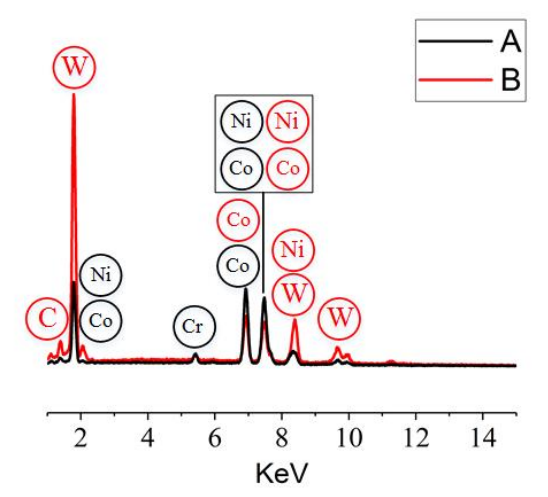

(d)

Figure 8. Chemical composition analysis conducted by Energy-dispersive X-ray spectroscopy: (a) studied positions; (b) EDS spectra on the dimple produced by 1 pulse; (c) studied positions; (d) EDS spectra on the one produced by 15 pulses.

\section{Conclusions and Perspectives}

In the present research work, two cemented carbide grades were machined by femtosecond laser with increasing pulse number. The influence of a laser machining parameter, i.e., pulse number, on the cemented carbide was studied in terms of geometrical properties, and surface integrity was assessed as an additional inspection. There are some important remarks: 
- The depth of the produced dimples increases approximately proportionally to the applied pulse number, but greater depth and a smaller laser-affected zone were achieved by VN77 (large grains) compared to VN76 (small grains). The depth increase rate of VN77 (large grains) is higher than that of VN76 (small grains). This could be a result of the different microstructures of these two grades; specifically, the grade with smaller grain size has a higher ablation threshold. The diameters of laser affected zones increase slightly along with the pulse number, and this is due to the deviation increase between the laser focus point and the point of laser-matter reaction when the ablation increases. Within this context, it is necessary to supply a position correction as a function of the pulse number for precision requirements.

- The appearance of a crown-like structure is a side effect that becomes increasingly important with the increase of the pulse number. This is caused by repetitive melting and redeposition at the edge of the Gaussian laser beams, where the energy decreases when the laser-matter reaction point moves forward from the focus point. It is then advisable to use fewer laser pulses and correct the laser focus point in order to reduce the formation of crown-like structures.

- Regarding the cross-sectional analysis, a similar damage mechanism was found for both gradesgrain cracks and binder melting - and no oxide was produced by the fs-laser. Damage occurred only at the very shallow subsurface for both grades, and side effects accumulated only slightly when the applied laser pulses increased. However, grains of VN77 (large grains) suffered from more pronounced damage compared to VN76 (small grains) under identical laser configuration. The microstructure of the cemented carbides could be the reason; therefore, it is suggested that cemented carbides with large grain sizes be ablated with less pulse energy.

In the future, it is necessary to compare the influence of machining parameters under different laser regime, such as a nanosecond laser. Moreover, different cemented carbide grades could also be involved, especially with different microstructures, to systematically study the influence of material microstructure on the laser ablation.

Acknowledgments: The work leading to this publication was supported by the German Academic Exchange Service (DAAD) with funds from the German Federal Ministry of Education and Research (BMBF) and the People Program (Marie Curie Actions) of the European Union's Seventh Framework Program (FP7/2007-2013) under REA grant agreement No. 605728 (P.R.I.M.E.-Postdoctoral Researchers International Mobility Experience). The authors are grateful for the material supplier Saar-Hartmetall und Werkzeuge GmbH. Finally, this contribution has also been partly funded by the Spanish Ministry of Economy and Competitiveness through Grant MAT2015-70780-C4-3P (MINECO/FEDER).

Author Contributions: Shiqi Fang, Luis Llanes and Dirk Bähre conceived and designed the experiments; Shiqi Fang, Chia-Jui Hsu and Sven Klein performed the experiments; Shiqi Fang analyzed the data; Luis Llanes and Frank Mücklich contributed reagents/materials/analysis tools; Shiqi Fang and Luis Llanes wrote the paper.

Conflicts of Interest: The authors declare no conflict of interest.

\section{References}

1. Wolfe, T.A.; Jewett, T.J.; Singh Gaur, R.P. Comprehensive Hard Materials. In Comprehensive Hard Materials; Elsevier: Oxford, UK, 2014; pp. 185-212.

2. Cardarelli, F. Ceramics, Refractories, and Glasses. In Materials Handbook: A Concise Desktop Reference; Springer: London, UK, 2008; pp. 593-689.

3. Exner, H.E. Physical and chemical nature of cemented carbides. Int. Met. Rev. 1979, 24, 149-173. [CrossRef]

4. Gurland, J. New scientific approaches to development of tool materials. Int. Met. Rev. 1988, 33, 151-166. [CrossRef]

5. Egashira, K.; Hosono, S.; Takemoto, S.; Masao, Y. Fabrication and cutting performance of cemented tungsten carbide micro-cutting tools. Precis. Eng. 2011, 35, 547-553. [CrossRef]

6. Schmitt, C.; Bähre, D. An approach to the calculation of process forces during the precision honing of small bores. Procedia CIRP 2013, 7, 282-287. [CrossRef]

7. Geiger, M.; Popp, U.; Engel, U. Excimer Laser Micro Texturing of Cold Forging Tool Surfaces-Influence on Tool Life. CIRP Ann. Manuf. Technol. 2002, 51, 231-234. [CrossRef] 
8. Etsion, I. State of the Art in Laser Surface Texturing. J. Tribol. 2005, 127, 248-253. [CrossRef]

9. Jacobson, S.; Hogmark, S. Surface modifications in tribological contacts. Wear 2009, 266, 370-378. [CrossRef]

10. Fang, S.; Herrmann, T.; Rosenkranz, A.; Gachot, C.; Marro, F.G.; Mücklich, F.; Llanes, L.; Bähre, D. Tribological Performance of Laser Patterned Cemented Tungsten Carbide Parts. Procedia CIRP 2016, 42, 439-443. [CrossRef]

11. Fang, S.; Llanes, L.; Klein, S.; Gachot, C.; Rosenkranz, A.; Bähre, D.; Mücklich, F. Frictional Performance Assessment of Cemented Carbide Surfaces Textured by Laser. IOP Conf. Ser. Mater. Sci. Eng. 2017, 258, 012006. [CrossRef]

12. Klein, S.; Fang, S.; Bähre, D. Analysis of Different Surface Structures of Hard Metal Guiding Stones in the Honing Process. Procedia Manuf. 2017, 10, 265-275. [CrossRef]

13. Dumitru, G.; Lüscher, B.; Krack, M.; Bruneau, S.; Hermann, J.; Gerbig, Y. Laser processing of hardmetals: Physical basics and applications. Int. J. Refract. Met. Hard Mater. 2005, 23, 278-286. [CrossRef]

14. Dumitru, G.; Romano, V.; Weber, H.P.; Sentis, M.; Marine, W. Femtosecond ablation of ultra-hard materials. Appl. Phys. A Mater. Sci. Process. 2002, 74, 729-739. [CrossRef]

15. Li, T.; Lou, Q.; Dong, J.; Wei, Y.; Liu, J. Modified surface morphology in surface ablation of cobalt-cemented tungsten carbide with pulsed UV laser radiation. Appl. Surf. Sci. 2001, 172, 331-344. [CrossRef]

16. Yao, Y.L.; Chen, H.; Zhang, W. Time scale effects in laser material removal: A review. Int. J. Adv. Manuf. Technol. 2005, 26, 598-608. [CrossRef]

17. Li, T.; Lou, Q.; Dong, J.; Wei, Y.; Liu, J. Phase transformation during surface ablation of cobalt-cemented tungsten carbide with pulsed UV laser. Appl. Phys. A 2001, 73, 391-397. [CrossRef]

18. Fang, S.; Llanes, L.; Bähre, D. Wear Characterization of Cemented Carbides (WC-CoNi) Processed by Laser Surface Texturing under Abrasive Machining Conditions. Lubricants 2017, 5, 20. [CrossRef]

19. Haustrup, N.; O'Connor, G.M. The influence of thin film grain size on the size of nanoparticles generated during UV femtosecond laser ablation of thin gold films. Appl. Surf. Sci. 2013, 278, 86-91. [CrossRef]

20. Costa, H.L.; Hutchings, I.M. Hydrodynamic lubrication of textured steel surfaces under reciprocating sliding conditions. Tribol. Int. 2007, 40, 1227-1238. [CrossRef]

21. Nakano, M.; Korenaga, A.; Korenaga, A.; Miyake, K.; Murakami, T.; Ando, Y.; Usami, H.; Sasaki, S. Applying micro-texture to cast iron surfaces to reduce the friction coefficient under lubricated conditions. Tribol. Lett. 2007, 28, 131-137. [CrossRef]

22. Leitz, K.H.; Redlingshöfer, B.; Reg, Y.; Otto, A.; Schmidt, M. Metal ablation with short and ultrashort laser pulses. Phys. Procedia 2011, 12, 230-238. [CrossRef]

23. $\mathrm{Xu}, \mathrm{X}$. Phase explosion and its time lag in nanosecond laser ablation. Appl. Surf. Sci. 2002, 197-198, 61-66. [CrossRef]

(C) 2018 by the authors. Licensee MDPI, Basel, Switzerland. This article is an open access article distributed under the terms and conditions of the Creative Commons Attribution (CC BY) license (http://creativecommons.org/licenses/by/4.0/). 